folk/ed. Derg, 2020; 26(2): 297-316

DOI: $10.22559 /$ folklor.1150

\title{
Kazak, Türkmen ve Kıbrıs Türklerinin Halk İnançları ile Gelenekleri Üzerine Karşılaştırmalı Bir İnceleme*
}

\author{
A Comparative Perspective of Folk Beliefs and \\ Traditions of Kazakhs, Turkmens and Turkish Cypriots
}

\author{
Mustafa Yeniasır** $^{* *}$ \\ Burak Gökbulut ${ }^{* *}$ \\ Adem Öger ${ }^{* * *}$
}

\begin{abstract}
$\ddot{\mathbf{O z}}$
İnanç olgusu en eski devirlerden günümüze kadar insanların temel sosyal ihtiyaçlarından biri olmuş ve tarih boyunca milletlerin kültürlerinin şekillenmesinde önemli bir rol oynamıştır. Türk kültür atlasının oluşumunda da çeşitli dinlerin, inançların ve inanç sistemlerinin etkisi olmuştur. Sözgelimi en eski çağlarda etkisini gösteren animizm, totemizm, daha sonraları Şamanizm, Gök Tanrıcılık ve en sonda da Müslümanlık kültürün şekillenmesinde önemli bir rol oynamış ve halk inançlarının te-
\end{abstract}

Geliş tarihi (Received): 16.12.2019 - Kabul tarihi (Accepted): 10.03.2020

Çalışma 20-21 Nisan 2019 tarihlerinde Saraybosna'da düzenlenen III. Uluslararası Sosyal Araştırmalar ve Davranış Bilimleri Sempozyumunda bildiri olarak sunulmuş ancak yayınlanmamıştır. Makale, söz konusu bildirinin yeniden gözden geçirilmiş ve genişletilmiş şeklidir.

*** Doç.Dr., Yakın Doğu Üniversitesi Türkçe Eğitimi Bölümü. mustafa.yeniasir@neu.edu.tr. ORCID ID: 00000002-9196-1805.

**** Doç.Dr., Yakın Doğu Üniversitesi Türk Halkbilimi Bölümü. burak.gokbulut@neu.edu.tr. ORCID ID:0000-00033968-9207

***** Doç.Dr., Nevşehir Hacı Bektaş Veli Üniversitesi Türk Halkbilimi Bölümü. adem.oger@nevsehir.edu.tr. ORCID ID: 0000-0003-1278-2110. 
mellerini oluşturmuştur. Çalışmanın araştırma alanı olarak belirlenen Kazakistan, Türkmenistan ve Kuzey Kıbrıs’ta da özellikle animizm, totemizm, Şamanizm, Gök Tanrıcılık ve Müslümanlığın halk inançlarına kaynaklık ettiği söylenebilir. Makalede her üç bölgenin halk inançları söz konusu çerçevede araştırılıp tespit edilmeye çalışılmıştır. İnanç ve âdetlerin tespitinde öncelikle literatür taraması yapılmış, veriler doküman analizi tekniğiyle toplanmış ve tespit edilen verilerin doğrulanmasında kaynak kişilerle karşılıklı görüşmeler yapılmıştır. Karşılıklı görüşmelerde kaynaklarda tespit edilen inançların halen geçerliliğini koruyup korumadığı sorgulanmış ve sonuçlar çalışmada belirtilmiştir. Çalışmanın amacı Kazak, Türkmen ve Kıbrıs Türklerinin halk inançlarını karşılaştırmak, bunların benzerlik ve farklılıklarını belirlemek ve bu inançları yorumlamaktır. Bu amaçtan yola çıkılarak yapılan incelemede Kazakistan ve Türkmenistan'da halk inançları ve âdetlerin birçoğunun halen yaygın olarak toplum hayatında etkisini sürdürdüğü, Kıbrıs Türklerinde ise bunların uygulanmasında zayıflamalar ve kaybolmalar olduğu belirlenmiştir. İncelemeler sonucunda inançların temelinde ağırlıklı olarak Türklerin inanmış olduğu eski dinler, inanç sistemleri ve İslamiyet'in bulunduğu görülmüştür.

Anahtar sözcükler: Kazak Türkleri, Türkmen Türkleri, Kıbrıs Türkleri, halk inançları, gelenek, uygulamalar

\begin{abstract}
The phenomenon of belief has been among the most fundamental social needs of people from the oldest ages to date and played an essential role in shaping the cultures of nations throughout history. In the formation of Turkish cultural map, various religions, beliefs and belief systems have been influential. For example, in the oldest times, animatism, totemism, and later Shamanism and Sky God religion, and finally Islam, have played essential role in the shaping of culture and laid the foundations of folk beliefs. It can be said that in Kazakhstan, Turkmenistan and Northern Cyprus, which are determined as the study area of the research, especially animitism, totemism, Shamanism, Sky God religion and Islam served as the sources of folk beliefs. In this article, attempt was made to examine the folk beliefs of all three regions and determine them within this framework. In the determination of beliefs and customs, the literature was first searched, the data were collected by document analysis technique and mutual interviews were conducted with the source persons in verifying the data. During the interviews, it was questioned whether the beliefs found in the sources still maintain their validity and the results were stated in the study. The aim of this study is to compare the folk beliefs of Kazakh, Turkmen and Turkish Cypriots, to determine their similarities and differences and to interpret these beliefs. Based on this aim, it was determined that most of the folk beliefs and customs in Kazakhstan and Turkmenistan still have a widespread effect on the community life whereas their application in the Turkish Cypriots is weakened and disappeared. As a result of the analysis, it has been seen that the beliefs are predominantly based on the old religions, belief systems and Islam, which the Turks have believed.
\end{abstract}

Keywords: Kazakh Turks, Turkmens Turks, Cypriot Turks, folk beliefs, tradition, practices 


\section{Extended abstract}

The religion and belief systems that Turks have believed throughout history, such as animism, totemism, Shamanism, Tengrism, Islam and such elements as sacred water, fire, nature and ancestral cult are the sources of today's folk beliefs. Today, while public beliefs and customs are kept alive in social life in Kazakhstan and Turkmenistan, the Turkish Cypriots have weakened and even disappeared in the implementation of customs and beliefs due to the changing living conditions. Despite the fact that the Cossacks were under the sovereignty of the Russians and the Chinese for a long time, they continue to live in line with these traditions, as they have preserved their traditions very firmly. On the other hand, although Turkmenistan is under the influence of different cultures, customs and beliefs continue effectively in social life. In the research, many similarities were found especially in beliefs and customs, which belong to the transitional periods of life such as birth, childhood, marriage and death. In pre-natal beliefs and practices, it was observed that mothers without children visited the tomb, made sacrifices, tied cloth to sacred places and trees and lit candles. In order for the child's gender to be a boy or a girl, applications such visiting entombed saints, making a vow, placing a boy on the bed of the puerperant are common practices. Reaching God and respecting the ancestors underlying the cult of the ancestors lie at the heart of the visits to sacred places such as entombed saints and graves. Tying cloth can be thought to be related to the belief of life and animism in Turkish mythology. The burning of candles is related to the cult of fire and the Turks to consider the fire as sacred.

When the customs and beliefs after birth are examined, it is seen that there is a tradition of burning henna in Kazakh and Turkish Cypriots. It can be thought that henna originated from animism and expressed devotion to the believed holy power. Other common postpartum customs and beliefs are the baby's forty-day ceremony, salting and naming the baby. The number forty and related practices and beliefs have a very important place in Turkish culture. The number 40 is an important element in the folk narratives that have taken place in both the Shamanistic and Islamic belief systems. The tradition of naming is one of the oldest Turkish traditions, from ancient Turkish epics to folk tales. Azan was added to the tradition of naming along with Islam. Number 3, like number 40, is a number that has been in Turkish culture since ancient times and emphasizes the three-tiered universe design of the Turks. Common practice in all three cultures during childhood is circumcision. The general practice for circumcision is to make the circumcision at the age of 3,5, 7, which is the odd number. Even though odd numbers are considered masculine in Islamic thought, even numbers are considered feminine. In this sense, the selection of odd numbers in circumcision should be related to this. Among the common customs and beliefs during the marriage phase is the fact that the male side, who wants the girl, brings dessert on their visit before plight. Another belief in Kazakh and Turkmen is the laying of white fabric / carpet on the way to the bride's new home. In Turkish mythology and understanding, it is believed that the path of the bride will be happy and open in terms of the evocation of good lock and goodness by white color. The common practice in Cyprus and Turkmen is that the bride is fumigated while entering her house. This is an application of Shamanistic origin to protect the bride from evil and evil eye. In the applications related to the death phase, there are elements such as dead food and prayers $(3,7,40,52,1$ year), candle / light burning and mourning for 40 days in the room of 
the dead. It can be said that the belief in dead food and mourning is related to the belief of ancestor's cult and reflecting respect for ancestors.

It can be thought that burning candles in the room of the dead besides the dead meal is also related to the belief that the soul is not lost. In these three cultures, there are several common beliefs about benediction, luck and bad luck. For example, swallow is an animal that is considered to be auspicious between Kazak and Turkish Cypriots and is not harmed. Besides these, various animal bones, skulls, horns and horseshoes are also believed to bring good luck. Common beliefs about bad luck in the three cultures are in majority. For example, the owl crowing, the rooster crowing in the evening, howling the dog, seeing a black cat, spitting into the water or fire, trimming nails at night, mirror breaking, whistling are signs of bad luck. Spiritual and supernatural beings include the belief of the Alkarlsl (red woman) and evil spirits which can be found in almost entire Turkish world. Many practices related to the expulsion of evil spirits are based on Shaman practices and ancient Turkish beliefs. For example, metals such as knives and scissors are related to the holiness of iron in Turks, while lead casting and scare-lifting are related to shaman practices. As a result of interviews with the sources, it has been determined that many of the public beliefs and customs are still alive today in Kazakhstan and Turkmenistan. However, it has been observed that there are weaknesses in the implementation of customs and beliefs in Turkish Cypriots due to various socio-cultural reasons (change of society and family structure, etc.), and even some customs and beliefs do not continue. As can be seen, the main religions of Kazakh, Turkmen and Turkish Cypriot folk beliefs are predominantly ancient religions believed by Turks, belief systems, and to a lesser extent Islam, all of which affect every area of Turkish beliefs, social life and culture.

\section{Giriş}

Türk halk inançlarının geçmişi tarih öncesi dönemlere kadar uzanmaktadır. Türklerin inanmış olduğu çeşitli dinler, inanç sistemleri ve mitolojiden gelen bu inançların animizm, totemizm (Artun, 2012), su (Türky1lmaz, 2013), ateş (Düzgün, 2015), tabiat ve atalar kültü (Selçuk, 2010), Şamanizm (Eliade, 1999), Gök Tanrıcılık, İslamiyet vb. (Dikici, 2005) farklı kaynaklardan beslendiği söylenebilir. Bir kısım Türkler Budizm, Manihaizm ve Hıristiyanlık gibi farklı dinleri kabul etse de bunlar ortak halk inançları üzerinde kayda değer bir etki yaratmamış genele yayılamamıştır. Bu anlamda özellikle halk inançlarında İslamiyet öncesi din ve inanç sistemlerinin etkili olduğu görülmektedir.

İnanç kavramı, Akarsu'nun tanımına göre "Bir şeyi güvenle doğru sayma tutumudur. Buna göre, yeterince gerekçesi bulunmayan, kesin olmayan bir şeyi doğru sayma, akıl yoluyla genel geçer bir doğrulama yapmadan başkasının tanıklığı üzerine kurulmuş kanıtları, bir kuşku olmaksızın onaylamadır” (Akarsu, 1988: 104). Kaplan'ın tespitine göre ise "En yaygın anlamıyla bir şeyin varlığını veya doğruluğunu herhangi bir delil olmadan kabul etmek olan inanç, insan doğasının (fitrat, tabiat) önemli unsurlarından biri olup, fitri (doğal, tabii) bir olgudur" (Kaplan, 2017: 66). TDK sözlüğünde ise inanç "1. Yeterince gerekçesi bulunmayan, kesin olmayan bir şeyi doğru sayma; us yoluyla genel geçer bir doğrulama yapmadan, başkasının tanıklığı üzerine kurulmuş kanıtları, hiçbir kuşku duymaksızın onaylama.” (TDK Sözlük) diye tanımlanırken din “Tanrı'ya, doğaüstü güçlere, çeşitli kutsal varlıklara inanmayı ve tapınmayı sistemleştiren toplumsal bir kurum, diyanet” diye tanımlanmaktadır. 
Oldukça zengin bir kültürel sahip olan Türk topluluklarının geçmişten bugüne zenginleşip gelen ve halk hayatında geniş yer bulan halk inançları, gelenekleri, görenek ve âdetleri bulunmaktadır. Halk inançlarında en belirgin etkiyi İslamiyet öncesi din ve inanç sistemleri göstermektedir. Özellikle İslamiyet öncesi inanç sistemlerinden Şamanizm ve Gök Tanrı inancı bunda oldukça etkilidir. Bunun yanında su, ateş ve atalar kültü de bugünkü inançlara etki eden diğer unsurlardır.

Araştırma sahası olan Kazakistan, Türkmenistan ve KKTC'nin coğrafik ve demografik yapılarından burada bahsetmek de yerinde olacaktır. Kazakistan Cumhuriyetinin yüz ölçümü 2.724.900 km karedir. 2017 sayımına göre nüfusu 18.650 bin. Başkenti Astana (1997'den itibaren) olan Kazakistan'ı eski başkenti Almatı (Alma-Ata) şehridir. Kazakistan Cumhuriyetinin para birimi ise 1993 'ten itibaren Tenge'dir (Shauyenov 2018: 95). Türkmenistan Cumhuriyetinin yüz ölçümü ise 448,1 bin km karedir. Başkenti Aşkabat olan Türkmenistan'ın nüfusu 1993 yılı itibari ile 4.254 bindir (Tatlılığlu 1999: 208). Para birimi ise manattır. Kuzey Kıbrıs Türk Cumhuriyeti Akdeniz'in üçüncü büyük adası konumundadır ve yüzölçümü 3355 km'dir. Başkenti Lefkoşa olan KKTC'nin nüfusu 2007 itibariyle 268 bindir (Atasoy, 2011: 56 - 39). Para birimi ise Türk lirasıdır.

Üç ülkenin dini ise bugün İslamiyet'tir. Bu anlamda bu üç bölgede halk inançlarında hem İslamiyet öncesi hem de İslamiyet sonrası dinlerin etkisi görülmektedir. Ancak yaygın etki İslamiyet öncesi inançlardadır. Kazakistan ve Türkmenistan'da halk inançları ve âdetler sosyal hayatta yaygın olarak yaşatılırken Kıbrıs Türklerinde değişen yaşam şartlarının etkisiyle âdet ve inançların uygulanmasında zayıflamalar hatta bazılarında kaybolmalar görülmektedir. Kazaklar "iki yüz yıldan fazla bir süre Rus, Çin ve Kalmukların fiili egemenlikleri altına girmelerine rağmen geleneklerini çok sağlam bir biçimde korudukları için günümüzde de bu gelenekler doğrultusunda yaşamaya devam ettirdikleri” (Kapağan ve Bacaklı, 2017: 731) görülmektedir. Türkmenistan'da farklı kültürlerin etkisi altına girilmesine karşın âdet ve inançlar sosyal hayatta etkin bir şekilde devam etmektedir.

\section{Araştırmanın metodolojisi}

\section{Veri toplama ve analiz yöntemi}

Veri toplamada her üç bölgedeki inanç ve âdetlerin tespitindelitaratür taraması yapılmış, verilerdoküman analizi tekniğiyle toplanmış ve tespit edilen verilerin doğrulanmasında kaynak kişilerle karşılıklı görüşme yöntemi (Ekici, 2004: 70) uygulanarak kaynak kişilere söz konusu inançlarla ilgili sorular yöneltilmiştir.

\section{Çalışmanın amacı}

Çalışmanın amacı, Türklerin yüzyıllardır yurt edindikleri Orta Asya’nın merkezi konumunda bulunan ve özellikle Rus kültürünün etkilerine maruz kalan, Kazak Türkleri (Kıpçak grubu) ile Türkmen Türklerinin (Oğuz grubu) halk inançları ile Orta Asya'dan oldukça uzak bir coğrafyada bulunan ve tarihî süreç içerisinde çok farklı kültürlerle (İngiliz, Yunan, Maronit vs.) etkileşim içerisinde bulunan Kıbrıs Türklerinin halk inançlarını karşılaştırarak benzerliklerle farklılıkları ortaya koymak ve bu inançları yorumlamaktır. 


\section{1. İnceleme}

$\mathrm{Bu}$ kısımda elde edilen bulgular verilirken belirli bir sınıflamadan hareket edilmiştir. İnançlar hayatın farklı evrelerine bağlı olarak ortaya çıkan, gelişen ve uygulanan unsurlardır. $\mathrm{Bu}$ anlamda inançlar öncelikle doğum, çocukluk, evlenme ve ölüm evrelerine göre sınıflanmış ve karşılaştırılmıştır. Ayrıca insan ve toplum hayatının genelini ilgilendiren uygulama ve inançlar (yağmur duası, nazar, kurban vs.) da bu sınıflamaya dahil edilmiştir.

\subsection{Hayatın evrelerine bağlı halk inançları:}

Hayatın evreleri olan doğum, çocukluk, evlenme ve ölüme bağlı olarak birçok uygulama ve inanç toplum hayatında yer etmiş ve hayatı şekillendirmiştir. Burada her üç ülkede doğumdan başlanarak hayatın geçiş dönemlerine bağlı benzer inanç ve uygulamalar verilecektir.

\subsubsection{Doğum evresi (Öncesi, hamilelik esnası, sonrası)}

1.1.1.1. Doğum öncesi: Türkmen ve Kıbrıs Türklerinde çocuğu olmayan anneler için çok çeşitli uygulama ve inançlar mevcuttur. Bunlardan en yaygın olanı türbe ve yatır ziyaretleridir (Bilgin, 2005: 123; Mear,1992: 19; KK24, KK13). Kazaklarda türbe ve yatırlar yanında kutsal yerleri ve mezarları da gezen baksiler ziyaret edilir (Kalafat 1999: 66; KK3). Ayrıca çocuğu olmayan kadın, kendi akrabalarından olan bir çocuğu koynuna alarak yatarsa çocuğu olacağına inanılmaktadır (KK11, KK3).

Türkmenistan'da çocuğu olmayan kişiler mollalara, îşanlara veya yatırlara giderler, oralarda yedi defa türbenin etrafında dolaşır, orada yatır, kurban keser, çaput bağlar ve para koyarlar (Dinç ve Çakır, 2008: 85; Bilgin, 2005: 123; KK27, KK29). Kıbrıs'ta ise gebe kalmak için yatırlara gidilip mum yakılır, ağaçlara bez bağlanır ve dua edilir. Bunun yanında "adetin 3. gününde kor kömüre mezdeki koyarak altını tütsülemek, çocuk sahibi kadının avcundan su içmek, adak adamak, elma okutup yemek gibi daha birçok uygulama bulunmaktadır" (Mear, 1992: 19; Peler, 2013: 2043; KK12, KK22). Kazakistan' da ise "kadının çocuğu olmazsa çocuğu çok olmuş ve ölen bir kadının külotu verilir. Bu külot evdeki sandığın dibine saklanır” (Y1lmaz, 2008: 426; KK9).

Doğacak çocuğun cinsiyetini belirlemek (kız veya erkek olması için) içinse Türkmenler yatırlara giderler (Bilgin 2005: 123; KK30, KK26). Kıbrıs Türklerinde ise erkek çocuk sahibi olmak için çocuksuz kadın adına kesilen kurbanın kuşağını bir mezara koyup 'Al kuşağı, ver uşağı' denilmesi, ziyaret yerlerine gidilmesi(türbe), adak adanması, loğusa kadının yataktan kalkma töreni sırasında yatağa erkek çocuk oturtup ondan sonra kalkılması gibi uygulama ve inançlar söz konusudur (Mear, 1992: 22; KK13, KK18, KK23).Kazak Türklerinde ise erkek çocuk doğurmak isteyen kadın silah, bıçak vb. gibi eşyaları; kız çocuk doğurmak isteyen ise toka, küpe, bilezik vb. gibi eşyaları yastığının altına koyarak uyur. Bir yere misafirliğe giderken yiyecek götürürse, kız çocuğu olur diye kendi götürdüğü yiyeceklerden yemez (KK11).

1.1.1.2. Hamilelik süreci: Doğumla ilgili inançlar her üç toplumda da çok çeşitlidir. $\mathrm{Bu}$ inançlar doğum öncesinden başlayarak doğum sırasına ve sonrasına kadar uzamaktadır. Örneğin; Kazak ve Kıbrıs Türklerinde hamilelik sürecinde ekşi gıdalara aşeren kadının kız çocuğu, tatlı gıdalara aşeren kadının ise oğlan çocuğu doğuracağına inanılır (Kalafat, 1999: 
66; Çeltikçi, 2009: 515; KK10, KK5, KK14, KK21). Çocuğun cinsiyetini belirlemede farkl1lıklar olsa da usulen birbirine benzer uygulamalar yapılmaktadır (Çeltikçi, 1999: 520).

Doğum öncesi diğer bir Kazak inancına göreyse "Aşeren annenin isteği karş1lanmaz ise bebeğinin sol veya sağ yanağında bir çukur oluşur” (Kalafat, 1999: 69; KK10, KK8). Yine Kazak ve Kıbrıs Türklerinde aşeren kadının isteği karşılanmazsa aşerilen şey doğacak bebeğin vücudunda iz olarak çıkacağına inanılır (Bağışkan, 1997a: 45; KK21, KK15KK6, KK2). Yine yine Kazak Türklerinde kadın hamileyken aşerdiği yiyeceği yemezse çocuk doğduktan sonra ağzının suyunun akacağına inanılır (KK11). Ayrıca hamileyken deve sütü içmek ve etini yemek iyi karşılanmaz. Yenirse hamile olan kadının doğumunun uzun süreceğine ve zorlanacağına dair inançlar mevcuttur (KK11).

Diğer bir inanca göre Kazak, Kıbrıs ve Türkmen inancına göreyse kadın hamileyken çirkin, sarhoş veya hastalıklı kimselere bakmamalıdır. Aksi takdirde doğacak çocuk da bakılan kişiye benzeyebilir (Kalafat, 1999: 66; Çeltikçi, 2009: 514, Mear, 1992: 24; Bağışkan, 1997a: 44; Tatlılığlu, 2000: 156; KK2, KK5, KK16, KK20, KK25, KK28). Doğum esnasındaki başka bir inanca göre de Kıbrıs ve Türkmen inançlarında hamile kadın çirkinleşirse kız, güzelleşirse erkek çocuk doğurur (Mear, 1992: 26,28; Tatlılıoğlu, 2000: 162; Koca, 2017: 546; KK17, KK20, KK25, KK28).

1.1.1.3. Sonrası: Doğumdan sonra kına yakma geleneği Kazak ve Kıbrıs Türklerinde bulunmaktadır. Kazaklarda bebek kırklandığı zaman kına yakılırken (Kalafat, 1999: 67; Çeltikçi, 1999: 515; KK1, KK14, KK16) Kıbrıs Türklerinde bebek altı aylığa geldiği zaman kınalanmaktadır (Yorgancıŏglu, 2000: 212; KK16, KK14, KK12). Kazaklarda kınanın yakı1masındaki amaç çocuğu görünmeyenlerin korkutmasından koruma inancıdır (Kalafat, 1999: 67; KK11). Bu uygulamaya bağlı olarak bebeğe nazar değmesin diye kazan karası sürüldüğü de görülmektedir (KK11).

Kazak Türklerinde doğum adetlerine bağlı olarak yapılan ve inanılan uygulamalar arasında çocuğun doğduktan sonra yaşamasına dair yapılan uygulamalar da vardır. Doğmadan ya da doğduktan sonra sürekli çocuğu ölen aile, daha sonra çocuğu doğduğunda yedi ihtiyarın arasından geçirir veya ölmesin diye çocuğuna “Tursun, Turar” vb. gibi isimler koyulmaktadır (KK11).

Kıbrıs Türklerindeki kına uygulamasında sağ el ve sol ayağa kına yakılır. Buradaki inanca göre insan iyilikleri sağ eliyle yapar, sol ayağın yanlış yapması da onun kınalanmasıyla önlenir (Yorganc1oğlu, 2000: 212; KK20, KK19).

“Kınanın kültürümüzdeki önemi, büyük ölçüde, adanmışlığı ifade eden sembolik bir vasıf kazanmasından ileri gelmektedir. Bir dileğin gerçekleşmesi amacıyla kutsal bir güce yönelik niyette bulunmak, kutsal sayılan bir şey uğruna kendini feda etmek, ant niteliğinde söz vermek anlamında kullanılan adama ve kurban vermenin ilk şekillerine animizmde rastlanır" (Tanribuyurdu, 2016: 103).

1.1.1.3.1. Bebeğin kırklaması: Kırklama inancı hemen tüm Türklerde var olan bir inançtır. Kadının doğum yaptığının kırkıncı günü yıkanması, kırkı çıkıncaya kadar doğum yapan kadının ve çocuğun evinden dışarı çıkmaması/çıkarılmaması ya da gelen misafirlere göste- 
rilmemesi, çocuğun kırklanması gibi birçok inanç her üç ülkede de görülmektedir (Çeltikçi, 1999: 520). Örneğin; Türkmenlerde kırk çıkarmada "doğumdan kırk gün sonra çocuk ve annesi kırk bir tane kaşı̆̆ın suyu ile yıkanmaktadır” (Tatlılığlu, 2000: 156; KK25, KK30, KK31). Kazaklarda da çocuk kırkını çıkardığında bebek kına katılmış suyla kırklanır. Bu şekilde "çocuğun görünmeyenlerin korkutmalarına karşı korunacağına inanılır" (Kalafat, 1999: 67; Rustemov, 1997: 52; KK1, KK3, KK9). Kıbrıs’ta ise loğusa topladığı kırk tane küçük taşı (her güne bir taş) kazanda kaynayan suya atar. Aynı anda 3 büyük taşı kazanın altındaki kömüre koyar. $\mathrm{O}$ arada loğusa kazanın buharında durur. Ebe 3 büyük taşı suya atar ve bu buharla loğusa hastalıklardan arınır. Sonunda ise loğusa bu suda yıkanır ve eğilerek taşları önden arkaya atar. Kadın bunu yapınca taş gibi sağlam olacağına inanır (Yorgancığlu, 2000: 198; Mear, 1992: 47; KK15, KK19).

1.1.1.3.2. Tuzlama: Her üç bölgede de belirli inançlara bağlı olarak tuzlama yapılmaktadır. Türkmenlerde "çocuk doğduğu zaman tuzlu suyla yıkamaktadır" (Tatlılığlu, 2000: 157; KK27, KK30). Kıbrıs Türklerinde ise tuz gömleği (Duzgöyneği) giydirme uygulamasına göre çocuk doğunca, iyi huylu-bilgili bir kişinin gömleği alınır, zeytinyağı sürülerek tuzlanan çocuğa yıkanacağı zamana kadar bu gömlek giydirilirdi. Çocuk tuzlanmazsa kuvvetsiz olacağına, teri ve ayaklarının kokacağına inanılırdı (Bağışkan, 1997a: 46; Mear, 1992: 32; KK12, KK15, KK23). "Kazak Türkleri arasında ise tuzlu su ile yıkama, yani, tuzlama işlemi bebeğin doğumunun ikinci günü yapılmaktadır” (Aça, 2001: 97-98; KK3, KK7). Tuzlamadaki sebep ise çocuğun vücudunda yara çıkmaması, derisinin sağlıklı olması içindir (KK11).

1.1.1.3.3. Ad koyma: Türkmenlerde çocuğun ismi, molla kulağına ezan okuduktan sonra dedesi tarafından konulmaktadır (Tatlılığlu, 2000: 157; KK28, KK31). Kıbrıs Türklerinde de ilk önce kulağına ezan okunur sonra da ismi kulağına üç kez söylenir (Mear, 1992: 38; KK13). Kıbrıs'ta diğer bir uygulama da çocuğun göbek adını ebenin vermesidir. Ebe önce çocuğun adını onun kulağına söyler. Üçüncü gün de ismin ne olduğunu annesine söyler ve aile ismi beğenmezse başka bir isim koyar (Yorgancığlu, 2000: 200; KK15, KK17). Kazaklarda da çocuğa kırkı çıktıktan sonra ad konulur. Ad koyan kişi Allahu Ekber diyerek üç kez ezan okuduktan sonra 'senin adın filanbay' diye, adı üç kez tekrarlar (Rustemov, 1997: 52; KK4, KK6). Özellikle her üç bölgede de 3 sayısının kullanımı Türklerin üç katmanlı evren tasarımıyla alakalı olmalıdır (Yıldırım, 2011: 1953; Bayat, 2006: 153). Ayrıca üçlülüğün İslam'daki tek tanrılı yapıda bile kendine yer bulabildiği görülmektedir (Schimmel, 2000: 78). Bu anlamada halk inançlarında 3 sayısı sıklıkla geçmektedir.

\subsection{2. Çocukluk evresi}

1.1.2.1. Sünnet: Çocukluk evresiyle ilgili en yaygın uygulamalardan biri sünnettir. Türk dünyasında genel bir inanç ve uygulama olarak çocuğun sünneti genelde tek sayılı yaşlarında yapılır (Çeltikçi, 2009: 516, 517). Kazaklarda, Türkmenlerde ve Kıbrıs Türklerinde de çocuğun sünnetinin 3, 5, 7 yaşlarında yapılmasına yönelik ortak bir uygulama vardır (KK1, KK7, KK20, KK14, KK24). "İslâm düşüncesinde vurgu genellikle tek sayılara yapılmıştır. Tek 
sayılar eril, çift sayılar dişil kabul edilmiştir" (Schimmel, 2004: 113). Buna ek olarak sünnet olan çocuğu ata bindirme de bu üç coğrafyada benzer bir uygulamadır (Kalafat, 2000: 54; Dinç ve Çakır, 2008: 63; Mear, 1992: 58; KK4, KK17, KK29).

\subsubsection{Evlenme evresi (Öncesi, esnası, sonrası)}

Türkmenlerde kız istemeye gelinirken ekmek veya şekerle gelinir. Ekmeğin bolluk içinken şeker de ilişkilerin güzel olması içindir (Gökçimen, 2010: 156; KK25, KK29). Kıbrıs'ta da kız istemeye gidilirken baklava veya tatlı şeyler götürülür. Kazaklarda ise söz kesmeye gidileceği zaman tatlı konuşulması amacıyla tatlı götürülür. Bunun yanında Kazaklarda kız istemeye gidileceği zaman kalın/kalım (deve, at, elmas kılıç, pahalı halı vs.) ve farklı hediyeler de götürülür (Çetindağ, 2007: 220, 225; KK3, KK8, KK10, KK18, KK13).

Gelin, düğünden sonra yeni evine getirilirken Kazaklarda yola beyaz kumaş, Türkmenlerde ise beyaz halı döşenir. Bu şekilde yolunun açık ve mutlu olacağına inanılır (Yılmaz, 2008: 428; Gökçimen, 2010: 157; KK3, KK8, KK10, KK25, KK29). Kıbrıs’ta böyle bir uygulamaya rastlanmamıştır. Türkmen ve Kıbrıs Türklerinde gelin, yeni evinin avlusuna girdiğinde üzerlik otu (Kıbrıs’ta zeytin yaprağı) ile tütsülenir. Bu uygulamanın gelini ve yeni evini kötülük ve nazardan koruyacağına inanılır (Tatlılığlu, 2000: 151-166; KK3, KK9, KK17, KK23, KK27, KK30).

\subsection{4. Ölüm evresi}

Türk kültüründe ölümle ilgili inanç ve uygulamaların çoğunun temelinde Gök Tanrıcılık, Şamanizm ve İslamiyet yatmaktadır.

Kazaklarda, Türkmenlerde ve Kıbrıs Türklerinde kişinin ölmesinin ardından belirli günlerde eşe dosta yemek verilir, ikramlarda bulunulur (sadaka) ve dua edilir. Kazaklarda bu günler 3., 7. ve 1.yıllığıdır. Türkmenlerde ise bu günler 3., 7., 40. ve 52. günlüğüdür (Gökçimen, 2010: 157; Vejdi, 2005: 116; Dinç ve Çakır, 2008: 55; KK3, KK4, KK7, KK28, KK26). Kıbrıslı Türklerde ise ölümü takiben ilk üç gece, 40. ve 52. günde ve 1 yıl dolduğunda ikram verilir ve mevlit okunur (Mear, 1992: 90; KK17, KK18).

Ölü gömme inançlarından biri de ölünün ruhunun ölümden 40 gün sonrasına kadar evden gitmediğidir. Bu inanca bağlı olarak Kazaklarda 40 gün boyunca evde mum yakılırken Kıbrıs Türklerinde 40 gün boyunca ölenin odasının ışığı açık bırakılır (Kalafat, 1999: 68; Mear, 1992: 89; KK4, KK7, KK17, KK18). Türkmenler de 40 gün yas tutmaya devam eder (Dinç ve Çakır, 2008: 59; KK26). Kazaklarda, Türkmenlerde ve Kıbrıs Türklerinde ortak şekilde kırk gün boyunca yas tutulup kırkıncı günü duası okunur (Kalafat, 1999: 71; Dinç ve Çakır, 2008: 59; Tatl1lığlu, 2000: 158; Mear, 1992: 90; KK4, KK7, KK26, KK17, KK18).

\subsection{Bereket, uğur ve uğursuzlukla ilgili inanışlar}

Kazakistan ve Kıbrıs Türkleri arasında uğurlu sayılan şeylerden biri kırlangıçlardır. Her iki bölgede de bu kuşun evlere yaptığı yuvalar yıkılmaz ve kuşlar kovulmaz. "Güney Kazakistan'da kırlangıçlar ölmüş ataların ruhları olabilir inancı ile taşlanıp kovulmazlar” 
(Güngör ve Köylü, 2014: 23; Y1lmaz, 2008: 424; KK11, KK18, KK20). Kıbrıs Türkleri arasında da kırlangıçlarının yuvasının yıkılmasının eve uğursuzluk getireceğine inanılır ve yuvaya dokunmazlar (KK16, KK12). Animizm kökenli olarak "Eski Türklerde, insan ruhları genellikle 'kuş' biçiminde düşünülmüştür. İnsanlara can vermeden önce bu ruhlar, gökte kuş olarak yaşarlar. İnsanlar ölünce de göğe uçarlar” (Artun, 2012: 2).

$\mathrm{Bu}$ kültürlerde uğurlu sayılan unsurlar yanında uğursuzluk getirdiğine inanılan unsurlar da mevcuttur. Bunlardan biri baykuştur. Kazak ve Türkmenlerde baykuşun kendisi ölümü çağrıştıran uğursuz bir kuş olarak kabul edilir (Sinmez ve Aslım, 2017: 214; KK8, KK6; KK24, KK27). Kıbrıs Türklerinde de baykuşun gece vakti ötmesi birinin öleceğine işarettir (Bağışkan, 1997: 37; KK12, KK17).Ayrıca Türkmenlerde saksağanın (alekke kuşu) gelip evin yanında ötmesi de bir uğursuzluk belirtisi sayılır (KK30).

Bunun yanında horozun akşam vakti ötmesi ve köpeğin uluması da Kazak (Sinmez ve Aslım 2017: 214; KK1, KK8) Kıbrıs (Bağışkan, 1997a: 37; KK19, KK12) ve Türkmen (Kalafat, 2014: 87; KK28, KK24) Türk kültüründe kötü habere veya birinin öleceğine yorumlanır. Tavuğun horoz gibi ötmesi ise Türkmen (Tatlılığlu, 2000: 161; KK26) ve Kıbrıs (Bağışkan, 1997a: 37; KK19) Türk kültürlerinde aileden birinin öleceğine işaret olarak kabul edilir.

Suya tükürmenin uğursuzluk getireceği inancı Kazak (Yılmaz, 2008: 419; KK11) ve Türkmen (Tatlılığlu, 2000: 153 ve Gökçimen, 2010: 151; KK30) Türklerinde bulunan bir inançtır. Bu, Türklerdeki su kültü inançları ve suyun kutsallığı ile alakalı olmalıdır. Bu inanç Kıbrıs'ta bulunmamasına karşın suya saygı Kıbrıs Türklerinde de bulunur. Örneğin, Kıbrıs Türklerinde hastalananların belirli pınarlarda gidip yıkandığı, burada mum yaktığı ve buradan aldıkları sularla evde de yıkandıkları bilinmektedir. Ayrıca bu bölgede bazı suların göz ve haseti uzaklaştırdığına inanılır (Bağışkan, 1997a: 65-66; KK22). Türkmenler de "Suyun geçmişten gelen kutsiyeti sebebiyle onu kirletmez ve saygı duyarlar" (Gökçimen, 2010: 152). Bu anlamda her üç ülkedeki inançlar ve uygulamalar su kültüne bağlı inançların bulunduğunu göstermektedir. Bunun yanında ateş kültüyle ilgili inançlar da bu bölgelerde bulunmaktadır. Örneğin, her üç bölgede de ateşe tükürmenin günah olduğu ve uğursuzluk getireceği inanc1 bulunmaktadır (Shauyenov, 2018: 133; Gökçimen, 2101: 151; Çobanoğlu, 1998: 105; KK11, KK7). Ayrıca Kazaklarda el silkelenince bereketin gideceğine inanılır (KK11).

Kazak ve Kıbrıs Türkleri arasında bir yolun kara kedi tarafından kesilmesi ve terliğin ters düşmesi uğursuzluk getirir (KK5, KK13). Ayrıca Kazaklar evin içinde ıslık çalınmasının evin bereketini alacağına ve şeytanı çağıracağına inanırken Kıbrıs Türkleri de gece 1slık çağırmanın eve şeytanları getireceğine inanır. Yine kediye vurmanın ve eziyet etmenin insana uğursuzluk getireceği ve insanın lanetleneceği inanc1 vardır (Yılmaz, 2008: 421, 424; KK5, KK6, KK8, KK20, KK16).

Kıbrıs Türkleri ve Türkmenlerin inancına göreyse kulak çınlaması birinin onu anacağına işarettir. Yine her iki toplumdaki inanca göre evden ayrılan misafirin ardından evin süpürülmesi misafirin bir daha gelmemesine yol açar (Tatlılığlu, 2000:160; Yorgancıŏlu, 2000: 305; KK15, KK22, KK29, KK31).

Her üç Türk boyunda da eşikte durmanın çeşitli şekillerde uğursuzluk getireceğine inanılır (Tatlılığlu, 2000: 153; Gökçimen, 2010: 157; Y1lmaz, 2008: 422; KK9, KK11, KK12, KK27). Kazak ve Kıbrıs Türklerinde uğursuzluk getirdiğine inanılan diğer bir şey de bir köpeğin kurt 
gibi ulumasıdır. Kazaklar köpeğin kurt gibi ulumasının kötü bir habere işaret ettiğine inanırken Kıbrıs Türkleri bunu köpeğin sahibinin öleceğine ve felakete bir işaret olarak yorumlarlar. Bu durumda Kazaklar kötü haberden korunmak için "Huday Kut Kara Gör” Allah'ım bizi koru diye dua ederken, Kıbrıs’ta kurt gibi uluyan köpekler genelde evden uzaklaştırılır (Kalafat, 1999: 68; Bağışkan, 1997a: 37; Bulun, 2004: 62-63; KK3, KK9, KK21, KK13).

Türkmenistan, Kazakistan'da ve Kıbrıs’ta aynanın kırılması da uğursuzluğa yorumlanır (Yorgancıoğlu, 2000: 304; KK2, KK17, KK30). Kazaklarda ayna kırıldığında ev sahibinin başında 3 defa döndürülür ve öyle atılır (Kalafat, 1999: 68; KK2).

Türkmenlerde, Kazaklarda ve Kıbrıs'ta diğer bazı ortak inançlar şöyledir: Gece tırnak kesmek günahtır ve uğursuzluk getirir, ayağının altı kaşınırsa yolculuğa çıkılacaktır, kulak çınlaması birinin sizin hakkında konuştuğuna işarettir, avcun kaşınması (Türkmen-Kazak: sağ el) para alacağına işarettir (Tatlılıoğlu, 2000: 159-160; Yılmaz, 2008: 422, 426-427; Yorgancioğlu, 2000: 302-304, KK27, KK30, KK3, KK14, KK16, KK19).

Türkmenlerde gece aynaya bakan insanın yüzünde nur kalmayacağına inanılırken, Kıbrıs'ta da gece aynaya bakmanın şeytanları çağıracağına inanılır. Kazaklarda da gece aynaya bakmanın insanın güzelliğini götüreceğine inanılır (Tatlılığlu, 2000: 153; Çobanoğlu, 1998: 107; Y1lmaz, 2008: 423; KK26, KK30, KK20, KK4).

Kazaklarda ve Kıbrıs’ta 1slık çalmanın uğursuzluk getirdiğine inanılır. Kazaklarda evin içinde 1slık çalınmasıyla evin bereketinin gideceğine ve şeytanları getireceğine inanılırken Kıbrıs Türklerinde gece 1slık çalınmasının şeytanları getireceğine inanılır (Yılmaz, 2008: 421, 422; Çobanoğlu, 1998: 107; KK8, KK21).

\subsection{Ruhani (Olağanüstü) varlıklarla ilgili inanışlar}

\subsubsection{Alkarısı}

Türk dünyasının hemen her bölgesinde bulunan alkarısı veya albastı inancı incelenen her üç kültürde de yer almaktadır. Bu kültürlerde alkarısı özellikle lohusaya ve kırkı çıkmayan bebeklere musallat olan kötü bir varlık olarak tasvir edilir (Bozkurt vd., 2014: 113). Kazaklarda kara ve sarı olmak üzere iki tür albastı vardır (Duvarc1, 2005: 129, KK9, KK11). Kara albastı ciddi ve ağırbaşlı bir ruh olduğuna inanılırken (Arslan vd., 2016: 204), sarı albastının doğum yapan kadının ve çocuğun ciğerini söküp suya atan bir ruh olduğuna inanılır (Sarı, 2017: 41). Alkarısının lohusaya ve bebeğe zarar vermemesi için çeşitli uygulamalar yapılır. Örneğin; Türkmenlerde lohusayı al basmaması için yanında bir erkek durur ve kadının yanına demir, süpürge ve ateş konur (Tatlılığlu, 2000: 156; KK25, KK28). Kıbrıs Türklerinde alkarısından korunmak için, bebeğin kırmızı tülbentle örtüldüğü, yatağa Kur'an-1 Kerim, ayna ve çuvaldız asıldığı, adet gören kadınların ziyarete kabul edilmediği görülmektedir (Yorgancığlu, 2000: 196; KK18, KK21). Bunun yanında anne ve bebeğin eşikte yatırılmaması (Bozkurt ve Arnaut, 2006: 58; KK18, KK21), yatağın yanına süpürge konulması, beşik üzerine al ve sarı tülbent konulması (Saracoğlu, 2013: 21; KK18), çocuğa ve lohusaya çivit sürülmesi, tuz gömleği giydirilmesi, odanın girişine deve eti asılması (Bağışkan, 1997b: 176; KK15), lohusa ve bebeğin yastığının altına biçak ve makas koyulması (Mear, 1992: 42; KK12) diğer koruyucu uygulamalardandır. Kazak Türklerinde de kadın ve çocuğun kırkı çıkıncaya kadar evden dışarı çıkması uygun görülmez ve bebek eve gelen misafirlere gösterilmez (Çeltikçi, 2009: 120; KK1, KK11). 


\subsubsection{Korkuluk çıkarma-kurşun dökme}

Kötü ruhlardan korunma ve kurtulmak için Kazak ve Kıbrıs Türkleri arasında yapılan diğer bir uygulama da kurşun dökmedir. Örneğin, Kazak Türklerinde bir şeyden korkan çocukların ağlamasını durdurmak için çocuğun başının üstünde bir kap su tutulur ve suya erimiş kurşun dökülür, üç kez dökülen kurşunun suda aldığı biçim çocuğun beşiğine veya kıyafetine iliştirilir (Güngör ve Köylü, 2014: 29; KK11, KK6), ayrıca kurşunun aldığ1 şekillere bak1larak çocuğun neden korktuğu öğrenilmeye çalış1lır (KK11). Kıbrıs Türklerinde de bir şeye karşı korku duyan çocuğun başı üzerine kırmızı tülbent ve onun üzerine de bir kap sus tutulur ve suya dökülen kurşunun aldığ 1 şekil çocuğun korku duyduğu şeyi gösterir. Kıbrıs’ta buna korkuluk kesmek/çıkarmak denir. Korkuluğu kesmeye gelen kadın niyet etikten sonra dua okur ve üç defa erimiş kurşuna üfler ve kurşunu suya döker. Bu andan sonra bu korkunun gideceğine inanılır (Yorgancığlu, 2000: 299; KK16, KK19). Türkmenlerde de nazar değmemesi için kurşun dökülür (Tatlılıoğlu, 2000: 162; KK25, KK31).

\subsection{Kurbanla ilgili inanışlar}

Bazı araştırmacılar kurbanı totemcilik öğesi olarak kabul ederken bir kısmı kabul etmez. Bitkiler ve ender olarak cansız şeyler (yıldızlar, bulut vs.) totem olabilirse de totem genellikle hayvandır. Totem ilişki kurulan tür ile bu türün çeşitli tasvirleridir. Bu tasvirler de kutsaldır ve kutsanır" (Artun, 2012:1).

Kazak (Kapağan ve Y1lmaz, 2017: 734) ve Türkmenlerde doğumdan sonra kurban kesilir. Türkmenlerde erkek çocuğa iki, kız çocuğa ise bir kurban kesilir (Çeltikçi, 1999: 516; Rustemov, 1997: 50; Tatlılığlu, 2000: 156; KK4, KK24). Kıbrıs Türklerinde ise doğumdan sonra kurban kesme geleneği çok yaygın olmamasına karşın doğumdan sonra bazı insanların koç kestiği bilinmektedir (Yorgancıŏ̆lu, 2000: 228; KK17). Kıbrıs’ta doğacak olan çocuğun erkek olması için çocuksuz kadın adına kesilen kurbanın kuşağını bir mezara koyup 'Al kuşağı, ver uşağı' denilmesi, şeklinde bir uygulama vardır (Mear, 1992: 22; KK17).

Türkmenler orman, ağaç, su ve kayalar için kurban sunmaya bugün de devam ederler. Bunun yanında yağmur duasında dileklerinin kabul olması üzerinde de kurban keserler (Tatlıl1oğlu, 2000: 160, 163; KK24, KK29). Yine Kibrıs'ta evin temeline kurban kesilmemesi nedeniyle evin perisinin doğan çocukları yaşatmadığına inanılır (Bağışkan, 1997b: 171; KK13). Kıbrıs'ta da çeşitli amaçlarla adak kurbanı kesilir: Bir dilekte bulunan, hastalığına çare bulamayan, çocuk sahibi olamayan vs. Adak kurbanları Hala Sultan vb. türbelerde kesilir. Adak dışında diğer iki ülkede olduğu gibi Kurban Bayramı'nda da kurban kesilir (Yorgancıoğlu, 2000: 228; KK13). Kazaklarda da çeşitli amaçlarla kurbanlar kesilir: Türbelerde dilekte bulunmak için, ölen ataların ruhuna saygı için, doğumdan sonra çocuk sahibi olunduğu için vs. (Shauyenov, 2018: 123; Kapağan ve Bacakl1, 2017: 734; KK4, KK10).

\subsection{Kutsal (ve kutsal sayılan) güçlerden istekte bulunmayla ilgili inanışlar}

\subsubsection{Türbe ve yatır ziyaretleri}

Türkmenlerde ve Kıbrıs’ta, türbelere mum yakma âdeti de eski âdetlerden biridir. Türkmenlerde eski çağlarda yalnız evliya sayılanların değil, başka ölülerin de mezarlarında yahut öldükleri yerlere mum yakmak veya ateş yakmak bir nevi kurban sayılmıştır (Tatlılığlu, 
2000: 161; Yorganc1oğlu, 2000: 228; Bağışkan, 1997a: 60; KK24, KK30, KK15, KK22, KK23). "Kazaklar arazide tek duran ulu ve yaşlı çam, kayın, ardıç ve çınar ağaçlarına adaklar adamakta, kurbanlar kesmekte, birtakım dualarla onlardan dilekte bulunmaktadırlar" (İnan, 1991: 257-259; KK15, KK23). Türklerde aksakallı dede, Hızır, pir ve evliyalara büyük sayg1 duyulmuş ve bunlar halk anlatı ve inançlarında geniş yer almıştır (Ögel, 1995: 89).

\subsubsection{Yağmur duası}

"Yağmur Duası, çok eski zamanlarda ortaya çıkmış olan ve şu anda da uygulanan bir gelenektir. Yağmur duasının ortaya çıkmasının en büyük nedeni, Türkmenlerin yerleşmiş bulundukları yerlerde suyun az olmasıdır" (Tatlılığlu, 2000: 163). Türkmenlerde yağmur yağması için çeşitli inançlara bağlı olarak uygulamalar yapılır. Örneğin, kurban kesilerek dinî vecibeler yerine getirilirse yağmur yağacağına inanılır (Tatlılıoğlu, 2000: 164; KK26, KK29). Yağmur duasına çıkıldığında bölgedeki herkesin katılımıyla tepelere ve yüksek yerlere çıkılır ve dualar okunur. Duaların söylenişis sırasında herkesin iştirak etmesi gerektiğine inanılır (Tatlılığ̆lu, 2000: 165). Yağmur duası uygulamaları Kazaklarda ve Kıbrıs'ta da yapılan uygulamalardır (Bağışkan, 1997a: 83-84; KK5, KK6, KK14, KK15). Türkmenlerde yağmur iyesine Burkut Ata denirken Kazaklarda yağmur iyesine Makul ve Makkay denilir (Gökçimen, 2010: 70; KK26, KK29).

\subsubsection{Bez bağlama}

Kıbrıs Türkleri arasında bir dilekte bulunmak için ağaçlara bez bağlama âdeti bulunmaktadır. Ancak dileği yerine gelen kişi bu bezi erken zamanda çözmek durumundadır, bez çözülmezse kısmetin geri gideceğine inanılır (Yorgancığlu, 2000: 302; Bağışkan, 1997a: 67; KK13, KK17). Bez bağlama aynı zamanda türbelerde de yapılır. Örneğin; çocuk sahibi olmak isteyenler yatır parmaklıklarına ve ağaçlara-çalılara bez bağlarlar (Mear, 1992: 19; KK13, KK17). Türkmenler ve Kazaklara da türbelere ve ağaç-çalılara çaput bağlarlar (Tatl1lığlu, 2000: 160; Yaman, 2005: 29; Shauyenov, 2018: 176; KK25, KK28, KK5, KK11).

\subsection{Kötü ruhlardan korunma, nazar ve göz değmesi}

Nazar inancı tüm Türk dünyasında yaygın olarak bulunan bir inançtır. Tüm Türk coğrafyasında nazar değmesini önlemek için çok çeşitli uygulamalar yapılmaktadır. Bu inanç Kazak, Türkmen ve Kıbrıs Türk coğrafyasında da bulunmaktadır. Bu üç bölgede de nazar değmemesi için icra edilen pratikler arasında belirli bitkilerle (üzerlik, zeytin yaprağı vs.) tütsü yapılması, tahtaya vurulması ve nazar boncuğu takılmasıdır. Kıbrıs’ta yapılan bazı uygulamalar arasında kurşun dökmek, hocaya okutmak, muska asmak, çocukların alnına zeytinyağı sürülerek ovmak, evin giriş kapısına at nalı, içinde yılan olan şişe ve boynuz asmak vardır (Yorgancıoğlu, 2000: 215; KK12, KK14, KK19, KK21). Kazaklar arasında ise nazar ve kötü ruhlara karşı korunma tılsımı olarak at kafası kullanılması (Çıblak, 2004: 111; KK11), çocuğun yüzüne kara sürülmesi, ulu kişilere bota (dua) okutulması, çocuğun beşiğine yarasa kuşunun tüyünün takılması, yeni alınan bir şeye kırmızı bir eşarp bağlanması gibi uygulamalar mevcuttur (Yılmaz, 2008: 420; KK3). Bunun yanısıra Kazak Türklerinde, nazar değen çocuğun başında üç defa tuz döndürü- 
lür ya da ekmek yedi parçaya bölünerek tuzla birlikte yedi bölgeye dokundururlarakalaslama yapılır. Alaslama aynı zamanda adrasman otu (üzerlik otu) ile de yapılmaktadır (KK11; KK2).

Türkmenlerde ise çocukları devamlı ölen aileler çocuklarını nazardan korumak için ona kötü isimler verirler, mavi taştan takılar takarlar (Dinç ve Çakır, 2008: 87; KK27, KK29), evlenecek kızın çeyizi taşınırken kızın eşarbı veya kıyafetinin bir parçasını yakarlar, gelinin düğün arabasına deve yününden siyah beyaz bir ip bağlarlar (Gökçimen, 2010: 156; KK26). Yine Türkmenlerde yeni ev yaparken göz değmesin diye evin temeline iğne, tuz ve kömür konulmakta, eve nazar değmesin diye balkona at, öküz veya koç kafası ve boynuzu asılmakta (Tatlılığulları, 2000: 163; KK24, KK27).Türkmen halk topluluklarında da bu eski çağlardaki inançların tezahürlerine şahit oluyoruz. Örneğin, at nalını uğur saymak, mavi boncuk ve maşallah nazarlıklardan takmak gibi inançların kökeni eski tarihlere kadar inmektedir (Tatlılığlu, 2000: 160; KK24, KK28).

Kazak ve Kıbrıs Türkleri arasında uğur getirdiğine ve koruyuculuğu olduğuna inanılan hayvan kemikleri bulunmaktadır. Kazaklarda nazar ve kötü ruhlara karşı at kafası kullanılırken (Çıblak, 2004: 111; KK11), Kıbrıs’ta kırkı çıkmamış çocuğu kırk basmasın diye çocuğun kaldığı odanın kapısına soğan ya da hayvan kemiği asılırdı. Ayrıca bebeğe nazar değmemesi için kundağına yılan kemiği iliştirilirdi (Mear, 1992: 45, 49; KK16, KK23). Bunun yanında Kıbrıs Türklerinin boynuzlu koç kafasını da nazardan korunmak amaçlı evlerinin giriş kapılarına astıkları bilinmektedir (Yorgancıoğlu, 2000: 215; KK16, KK20).

\section{Sonuç}

Kazakistan, Türkmenistan ve Kuzey Kıbrıs Türk Cumhuriyeti kapsamında yapılan bu çalışmada önemli ortaklıklar tespit edilmiş ve bunlar değerlendirilmeye çalışılmıştır. Kültürün yaşayan ve değişen bir olgu olduğu gerçeğinden hareketle literatür çalışması sonunda elde edilen verilerin güncelliği konusu ise göz önünde bulundurulan diğer bir husustur. Bu anlamda verilerin elde edilmesinin ardından söz konusu inançların günümüzdeki varlığı kaynak kişilerle yapılan karşılıklı görüşmeler sonucunda teyit edilmiş ve çalışmada halen her üç Türk toplumunda da varlığını sürdüren inançlara yer verilmiştir.

Araştırmanın sonucunda tespit edilen ve karşılaştırılan her üç bölgenin inançlarının ve âdetlerinin birbiriyle birçok benzerlik ve ortaklığı taşıdığı ve bunların ortak Türk kültürünün bir sonucu olduğu kanısına varılmıştır. Tespitler doğrultusunda yapılan sınıflamaya dahil edilen inançlar her üç kültürde benzer olacak şekilde verilmiş, ancak bazı uygulamalara iki bölgede rastlanılmıştır. Söz gelimi Kıbrıs Türkleri ve Kazaklarda olan bazı inanç ve uygulamaların bazıları Türkmenlerde tespit edilemezken bazılarının da Kıbrıs ve Türkmenlerde olup Kazak Türklerinde bulunmadığı tespit edilmiştir.

İnanış ve âdetlerin geneli değerlendirildiğinde bunların kökenlerinin ateş, su gibi tabiat kültleri ile atalar kültlerine, Şamanizm inanç sistemine ve bir kısmının da İslamiyet'e dayandiğı söylenebilir.

En baştan değerlendirmek gerekirse doğum, çocukluk, evlenme ve ölüm gibi hayatın geçiş dönemlerine ait olan inanç ve âdetlerde birçok benzerlik tespit edilmiştir. Doğum öncesi inanç ve uygulamalarda çocuğu olmayan annelerin türbe yatır ziyareti yaptığı, kurban kestiği, kutsal sayılan yerlere ve ağaçlara çaput bağladığı ve mum yakıldığı görülmüştür. Çocuğun 
cinsiyetinin erkek veya kız olması içinse yatırlara gidilmesi, adaklar adanması, loğusanın yatağına erkek çocuk oturtulması gibi uygulamalar yapılmaktadır. Yatır ve mezar gibi kutsal sayılan yerlerin ziyaretlerinin temelinde Tanrıya ulaşmak ve atalar kültünün temelinde yatan atalara saygı yatmaktadır. Ağaçlara çaput bağlama ise Türk mitolojisindeki hayat ağacı inanc1 ve animizm ile alakalı olduğu düşünülebilir. Mum yakmanın ise ateş kültüyle ve Türklerin ateşi kutsal sayması ile ilgilidir.

Doğum esnasındaki ortak inançlardan cinsiyet belirlemeye bağlı inançlara bakıldığında ortak bir inanç olarak hamile kadının ekşi gıdalara aşermesinin kız çocuğa tatlı gıdalara aşermesinin ise erkek çocuğa işaret ettiği tespit edilmiştir. Aşermeye bağlı olarak gelişen bir inanca göreyse hamile kadının canının bir şey çekmesi durumunda canı çektiği şey temin edilmezse çocuğun üzerinde iz çıkacağıyla ilgilidir. Bu hamile kadının isteklerinin karşılanmasına yönelik bir inanç olmalıdır. Hamilelik esnasındaki diğer bir ortak inanç da hamile kadının hamileyken çirkin, sarhoş veya hastalıklı kimselere bakmamasıyla ilgilidir. Çünkü inanca göre eğer bakarsa doğacak çocuk da bakılan kişiye benzeyebilir. $\mathrm{Bu}$ inanç hamile kadının ve bebeğinin korunmasına yönelik bir uygulama olmalıdır.

Doğum sonrası âdet ve inançlara bakıldığında Kazak ve Kıbrıs Türklerinde kına yakma geleneğinin olduğu görülmektedir. Kınanın animizm kökenli olduğu ve inanılan kutsal güce adanmışlığı ifade ettiği düşünülebilir. Ortak olan diğer doğum sonrası âdet ve inançlar ise bebeğin kırklanması, tuzlanması ve bebeğe ad verilmesidir. Kırk sayısı ve buna bağlı uygulama ve inançlar Türk kültüründe çok önemli bir yer tutmaktadır. Kırk sayısı hem Şamanistik hem de İslami inanç sisteminde yer edinmiş olan, halk anlatılarında formel sayı olarak geçen önemli bir unsurdur. Ad koyma geleneği eski Türk destanlarından, halk hikayelerine kadar yer edinmiş olan en eski Türk geleneklerindendir. Bu geleneğe İslamiyet'le birlikte ezan da eklenmiş ancak 3 formel sayısıyla eskiye bağlılık korunmuştur. 3 sayısı da 40 sayısı gibi Türk kültüründe eski devirlerden beri yer etmiş olan ve Türklerin üç katmanlı evren tasarımına vurgu yapan bir sayıdır.

Çocukluk evresinde her üç kültürde ortak olarak geçen uygulama sünnettir. Sünnet için genel uygulama sünnetin tek sayı olan 3, 5, 7 sayılarında yapılasıdır. İslam düşüncesinde tek sayılar eril kabul edilirken çift sayılar dişil kabul edilir. Bu anlamda sünnetin yapılmasında tek sayıların seçilmesi bununla alakalı olmalıdır.

Evlenme evresindeki ortak âdet ve inançlar arasında ise dünürcülük ve söz kesmeden kızı isteyen erkek tarafının gelirken tatlı getirmesidir. Kazak ve Türkmenlerde olan diğer bir inanç da gelinini yeni evine gelirken yoluna beyaz kumaş/halı döşenmesidir. Türk mitolojisi ve anlayışında beyaz/ak rengin uğur ve iyiliği çağrıştırmasıyla alakalı olarak gelinin yolunun da mutlu ve açık olacağına inanılır. Kıbrıs ve Türkmenlerdeki ortak uygulama ise gelinin evine girerken tütsülenmesidir. Bu, gelini kötülük ve nazardan korumak için yapılan Şamanistik kökenli bir uygulamadır.

Ölüm evresi ile ilgili uygulamalarda belirli günlerde verilen ölü yemeği ve edilen dualar (3, $7,40,52$, 1. yıl), ölünün odasına mum/ 1ş1k yakma ve 40 gün yas tutma gibi unsurlar bulunmaktadır. Ölü yemeği ve yas tutma inancının atalar kültü inancıyla alakalı olan ve atalara duyulan saygıyı yansıtan bir inanç olduğu söylenebilir. Ölü yemeğinin yanında ölünün odasına mum yakılması da animizm kökenli olan ruhun kaybolmadığı inancıyla ilgili olduğu düşünülebilir. 
$\mathrm{Bu}$ üç kültürde bereket, uğur ve uğursuzlukla ilgili birçok ortak inanç bulunmaktadır. Örneğin kırlangıç Kazak ve Kıbrıs Türkleri arasında uğurlu sayılan ve zarar verilmeyen bir hayvandır. Bunlar yanında çeşitli hayvan kemikleri, kafatasları, boynuzları at nalı da uğur getirdiğine inanılan şeylerdir.

Üç kültürde uğursuzlukla ilgili ortak inançlar çok daha fazladır. Örneğin; baykuşun ötmesi, horozun akşam vakti ötmesi, köpeğin uluması, kara kedi görülmesi, suya veya ateşe tükürülmesi, gece tırnak kesilmesi, ayna kırılması, ıslık çalınması uğursuzluğa işarettir.

Ruhani ve olağanüstü varlıklar arasında hemen tüm Türk dünyasında bulunan alkarısı inancı ve kötü ruhlar bulunmaktadır. Alkarısı inancı Türk mitolojisindeki üç katmanlı evren tasarımında kötü ruhların yaşadığına inanılan yer altı dünyasıyla alakalıdır. Kötü ruhların kovulmasıyla ilgili birçok uygulama ise Şaman pratikleri ve eski Türk inançları kaynaklıdır. Örneğin; bıçak, makas gibi metaller Türklerde demirin kutsallığı ile ilgili iken kurşun dökme ve korkuluk çıkarma Şaman pratikleri ile ilgilidir.

Kurbanla ilgili âdet ve inançlar her üç kültürde de görülmektedir. Kurban, doğumdan sonra çocuk sahibi olunduğu için, doğacak çocuğun erkek olması, yağmur yağması, evin sağlam olması (temele kan akıtma), hastalığa çare bulunması ve çocuk sahibi olunması için kesilir. Kurban kesme hem İslamiyet öncesi hem de İslamiyet sonrası inançlarla ilgili olan bir âdettir.

Her üç bölgede karşılaşılan türbe-yatır ziyareti, yağmur duası ve bez bağlama âdetlerinde esas olan kutsal veya kutsal sayılan güçlerden istekte bulunmadır. Türbe ziyaretleri atalar kültü temelli iken yağmur duası Şamanizm temelli, bez bağlama ise animizm temelli inanç ve âdetlerdir.

Kötü ruhlardan ve nazardan korunma inanç ve uygulamaları da eski Türk inançlarının izlerini taşıyan uygulamalardır. Nazardan korunmayla ilgili pratikler arasında nazar boncuğu takma-asma, tütsü yakma, kurşun dökme, hocaya okunma (İslami kökenli), muska asma ve at nalı asma gibi pratikler yer almaktadır.

Kaynak kişilerle yapılan görüşmeler sonucunda Kazakistan ve Türkmenistan'da günümüzde halk inançları ve âdetlerin birçoğunun halen yaygın olarak yaşatıldığı belirlenmiştir. Ancak Kıbrıs Türklerinde çeşitli sosyo-kültürel nedenlerle (toplum ve aile yapısının değişimi vs) âdet ve inançların uygulanmasında zayıflamalar olduğu, hatta bazı âdet ve inançların da devamlılığını sürdürmediği görülmüştür.

Görüldüğü üzere Kazak, Türkmen ve Kıbrıs Türk halk inançlarının temelinde ağırlıklı olarak Türklerin inanmış olduğu eski dinler, inanç sistemleri ve daha düşük oranda İslamiyet bulunmakta ve bunlar Türk inançlarının, sosyal hayatının ve kültürünün her alanına etki etmektedir.

\section{Kaynaklar}

Akarsu, B. (1988). Felsefe terimleri sözlü̆̆̈̈. İstanbul: İnkılap.

Arslan, A., Çelikkaya, Ş. ve Taşbaşı, A. (2016). Türk kültürü bağlamında Ağrı ili alkarısı inanmaları. Milli Ĕgitim Dergisi, S. 45 (212), ss. 201-210. 
Atasoy, A. (2011). Kuzey Kıbrıs Türk Cumhuriyeti'nin nüfus coğrafyası/Population geography of Turkish Republic of Northern Cyprus. Mustafa Kemal Üniversitesi Sosyal Bilimler Enstitüsü Dergisi, S. 8(15), ss. 29-62.

Bağışkan, T. (1997a). Çocuk yaşatmayan kadınlarla ilgili inançlar ve sağaltma uygulamaları. K. Kanol. (Haz.) Halkbilimi Sempozyumları II, Lefkoşa: KKTC. Milli Eğitim, Kültür, Gençlik ve Spor Bakanlığ 1 , ss. 33-110.

Bağışkan, T. (1997b). Karşıllaştırma yöntemiyle Kıbrıslı Tük ve Rumlarda ortak inanç ve uygulamalar. K. Kanol (Haz.) Halkbilimi Sempozyumları II, Lefkoşa: KKTC. Milli Eğitim, Kültür, Gençlik ve Spor Bakanlığı, ss. 165-193.

Bayat, F. (2006). Ana hatlarıyla Türk şamanlığı. İstanbul: Ötüken.

Bilgin, V. (2005). Gelenek ve din: Türkmenistan'ın dinî hayatında geleneğin rolü. Marife Dini Araştırmalar Dergisi, S. (2), ss. 101-124.

Bozkurt, İ. \& Arnaut, F. (2006). Yeniboğaziçi halk kültürü. Gazimağusa: Doğu Akdeniz Üniversites.

Bozkurt, Ö. D., Hadimli, A. ve Sevil, Ü. (2014). Günümüzde lohusalıkta devam eden albasması ve kırklama uygulamaları. Ege Üniversitesi Hemşirelik Fakültesi Dergisi, S. 30 (1), ss. 111-126.

Bulun, O. (2004). Bölgesel rivayetler inanç ve âdetlerimiz. Lefkoşa: Kansoy.

Çeltikci, O. (2009). Türk dünyası kültüründe doğum üzerine ortak uygulamalar. Journal of Azerbaijani Studies, ss. 511-521.

Çetindağ, G. (2007). Kazak Türklerinde evlenme geleneğine bağlı olarak gerçekleştirilen hediye alışverişi üzerine bir inceleme. Milli Folklor, S. 19 (76), ss. 218-231.

Çıblak, N. (2004). Halk kültüründe nazar, nazarlık inancı ve bunlara bağlı uygulamalar. Türklük Bilimi Araştırmaları, S. (15), ss. 103-125.

Çobanoğlu, Ö. (1998). Adalar Türklüğü folkloru: Kıbrıs ile Midilli, Girit, Sakız, İstanköy ve Rodos Türklerinin folklorundaki yapısal ve işlevsel ortaklıklar üzerine tespitler. Birinci Uluslararası Kıbrıs ve Balkanlar Türk Edebiyatları Sempozyumu Bildiriler Kitabı, Gazimağusa: Doğu Akdeniz Üniversitesi, ss. 101-114.

Dikici, M. (2005). Türklerde inançlar ve din. Ankara: Akçağ.

Dinç, A., ve Çakır, R. (2008). Türkmen kültürü ve Türkmenlerin sosyo-iktisadi düşüncesi. İstanbul: Ayrikotu.

Duvarc1, A. (2000). Türklerde tabiat üstü varlıklar ve bunlarla ilgili kabuller, inanmalar, uygulamalar. Bilig, S. (32), ss. 125-144.

Düzgün, Ü. K. (2015). Türk mitolojisinde ateş kültü. Türk mitolojisine giriş, ss. 147-160. Ankara: Gazi.

Ekici, M. (2004). Halk bilgisi (Folklor): Derleme ve inceleme yöntemleri. Ankara: Geleneksel.

Eliade, M. (1999). Şamanizm. İ. Birkan (Çev.). Ankara: İmge.

Gökçimen, A. (2010). Türkmen Irımları (Halk inanışları) ve işlevleri. Milli Folklor, S. 22(87), ss. 148-158. İnan, A. (1991). Makaleler ve incelemeler II. Ankara: Türk Tarih Kurumu.

Kalafat, Y. (1999). Kazakistan'daki Türk halk inançları. Milli Folklor, S. 11 (41), ss. 66-71.

Kalafat, Y. (2000). Baksilik ve Kazakistan'da Türk halk inançları. Türk Kültürü-Türk Kültürü Araştırmaları Dergisi, XXXVIII (441), ss. 49-55.

Kalafat Y. (2014). Esrarı ve Bektik Türkmenlerinde hayvanlarla ilgili halk inançları. Kültür Evreni Dergisi, S. 6 (21), ss. 79-93. 
Kapağan, E., ve Bacaklı, Y. (2017). Kazak Türklerinde terbiye edici bir unsur olarak alkış ve batalar. Itobiad: Journal of the Human\&Social Science Researches, S. 6 (2), ss. 731-740.

Kaplan, H. (2017). Dini İnanç, dini tasavvur, şüphe ve inançsızlık. Din psikolojisi. H. Apaydın (Ed.). ss. 65- 88. İstanbul: Lisans.

Koca, S. K. (2017). Türk kültürünün gelecek kuşaklara aktarılmasında sembollerin önemi (Doğum geçiş dönemi örneği). Türük Uluslararası Dil, Edebiyat ve Halk Bilimi Araştırmaları Dergisi, S. $1(11)$, ss. 530-554.

Mear, H. (1992). Kıbrıs Türk toplumunda doğum evlenme ve ölüm ile ilgili adet ve inanışlar. KKTC Milli Ĕ̈itim ve Kültür Bakanliğl. 22. Kitap.

Mehmet, A. (2001). Türk halk geleneğindeki doğum sonrası uygulamalara bir örnek: 'Tuzlama'. Milli Folklor, S. 13 (52), ss. 93-100.

Ögel, B. (1995). Türk mitolojisi (Kaynakları ve açıklamaları ile destanlar). C. II. Ankara: Atatürk Kültür, Dil ve Tarih Yüksek Kurumu Türk Tarih Kurumu.

Peler, G. Y. A (2013). Doğumla ilgili bazı âdetler bağlamında Kıbrıs Türklerinin etnik kökeni üzerine düşünceler. Turkish Studies-International Periodical for the Languages, Literature and History of Turkish or Turkic, S. 8, ss. 2041- 2052.

Rustemov, M. (1997). Kazak halk kültürü ve edebiyatından örnekler. V. Türk (Çev.). Türk Dünyası Dil ve Edebiyat Dergisi, S. (4).

Sarı, E. (2016). Efsane yaratıklar: Nefes kesen efsaneler. Antalya: Nokta.

Schimmel, A. (2000). Sayıların gizemi. M. Küpüşoğlu (Çev.). İstanbul: Kabalcı.

Schimmel, A. (2004). Tanrı'nın yeryüzündeki işaretleri: İslama görüngübilimsel yaklaşım. İstanbul: Kabalc1.

Selçuk, A. (2010). Horasanda eren Anadolu'da evliya: Acısu Sıraç Köyü örneğinde kahraman atalar kültü. Millî Folklor, S. 22 (87).

Shauyenov, D. (2018). Güney Kazakistan Kazaklarında ölüm ile ilgili inançlar ve ritüeller-Türkistan örneği (Yayımlanmamış Doktora Tezi). Kayseri: Erciyes Üniversitesi.

Sinmez, Ç. Ç., ve Aslım, G. (2017). İç Anadolu bölgesindeki hayvanlarla ilgili inanış ve uygulamalar üzerine bir değerlendirme. Bilig, S. 81, ss. 205.

Tanrıbuyurdu, G. (2016). Klâsik Türk şiirinde bir sembol dili olarak "Kına". Itobiad: Journal of the Human \& Social Science Researches, S. 5(1), ss. 102-115.

Tatl11ığlu, D. (1999). Türkmenistan'da sosyo-ekonomik yap1 ve dinî hayat. Cumhuriyet Üniversitesi Ilahiyat Fakültesi Dergisi, S.3, ss. 205-228.

Tatlılığlu, D. (2000). Türkmen ırımları (Halk inançları). Cumhuriyet Üniversitesi İlahiyat Fakültesi Dergisi, S. 4(1), ss. 1-15.

Türkyılmaz, A. (2013). Anadolu öncesi Türklerde su kültü ve günümüzdeki yansımaları. Bilim ve Kültür -Uluslararası Kültür Araştırmaları Dergisi, S. 1 (4), ss. 83-100.

Yaman, A. (2005). Türk dünyasında ziyaret kültürünün ortak bazı unsurları hakkında. Manas Üniversitesi Sosyal Bilimler Dergisi-Manas Üniversiteti Koomdik İlimder Jurnalı, S. 14, ss. 29-37.

Yıldırım, N. (2011). Türk halklarının destan yaratılarında üç dünya. Electronic Turkish Studies, S. 6 (3), ss. 1951-1965.

Yılmaz, M. A. (2008). Kazaklarda batıl inanışlar. Çukurova Üniversitesi Sosyal Bilimler Enstitüsü Dergisi, S. 17(3), ss. 417-430.

Yorgancioğlu, O. (2000). Kıbrıs Türk folkloru. G. Mağusa: Canbulat. 


\section{Elektronik kaynaklar}

Artun, E. (2012). Türklerde İslamiyet öncesi inanç sistemleri-öğretiler-dinler. Erişim adresi:http:// turkoloji.cu.edu.tr/HALKBILIM/erman_artun_inanc_sistemleri.pdf (erişim tarihi: 17.4.2019).

Güngör, H. \& Köylü, Bekir (2014). Türk halk inanışlart-ders notları. Kayseri: Erciyes Üniversitesi İlahiyat Fakültesi. http://bizdosyalar.nevsehir.edu.tr/4f4a3e1b4c0b 29c9505e0d4ac1757691/turkhalk-kulturu-3.pdf(erişim tarihi 16.04.2019).

Türk Dil Kurumu Türkçe sözlükhttp://www.tdk.gov.tr/index.php?option=com_bts\&arama= kelime\&guid=TDK.GTS.5ca9d73caf6729.41701824 (Erişim tarihi: 7.4.2019).

\section{Kazakistan ile ilgili kaynak kişiler:}

KK1: Gülnar Kadır,Doğu Türkistan/Karasu,1963, Öğretmen.

KK2: Nusiphan Bayzak, Doğu Türkistan/Karasu, 1962, Üniversite Mezunu, Muhasebeci.

KK3: Bekzade Kozhekeyeva, Kazakistan/Narınkol, 1961, Üniversite Mezunu, Akademisyen.

KK4: Aydos Kozhekeyev, Kazakistan,1961, Üniversite Mezunu,Mühendis.

KK5: Aziza Muhtarova, Kazakistan/Kızılorda,1953, Üniversite Mezunu, Emekli Öğretmen.

KK6: Gımınjan Aray, Doğu Türkistan/Nılk1, 1994, Üniversite Mezunu. Bilgisayar Mühendisi.

KK7: Bahtiyar Düsen, Kazakistan/Çimkent,1968, Üniversite Mezunu, Okul Müdürü.

KK8: Janar Tajekeyeva, Kazakistan/Öskemen,1970, Üniversite Mezunu, Öğretmen.

KK9: Nurjan Beysekeyev, Kazakistan/Aktau,1973, Üniversite Mezunu, Öğretmen.

KK10: Sara Janayeva, Kazakistan/Karagandı,1954, Üniversite Mezunu, Emekli Öğretmen.

KK11: Gulnaz Nusiphan, Doğu Türkistan/Gulca, 1997, Üniversite Öğrencisi.

\section{Kuzey Kıbrıs Türk Cumhuriyeti ile İlgili Kaynak Kișiler:}

KK12: Nilgün Toruntay, KKTC/Gazimağusa, 1954, Ev Hanımı.

KK13:Halim Arslan, KKTC/ Gazimağusa, 1930, Emekli Asker.

KK14:Münüre Gezercan, KKTC/Girne, 1944, İşçi Emeklisi

KK15:Meryem Karadoğan, KKTC/Lefkoşa, 1952, Ev Hanımı.

KK16:Hasan Köknar, KKTC/ Çamlıbel, 1932, Çiftçi.

KK17: Dürüsün Çelikesmer, KKTC/Lefkoşa, 1945, Ev Hanımı.

KK18:Mehmet Dağl1, KKTC/Gazimağusa, 1957, Çiftçi.

KK19:Soyal Taze, KKTC/ Gazimağusa, 1960, Emekli Polis.

KK20: Mukaddes Mermi, KKTC/Güzelyurt, 1926, Ev Hanımı.

KK21:Sabriye Akmandor, KKTC / Güzelyurt, 1947, Ev Hanımı.

KK22: Filiz Kocaoğlan, KKTC/, 1965, Ev Hanımı.

KK23: Sevim Atilla, KKTC/Girne, 1951, Ev Hanımı. 


\section{Türkmenistan ile İlgili Kaynak Kişiler}

KK24: Hudayberdi Olimov, Türkmenistan/Türkmenabat, 1974, Hasta ve Yașlı Bakıc1.

KK25: Gülnara Olimova, Türkmenistan/Türkmenabat, 1973, Hasta ve Yaşlı Bakıc1.

KK26: Arslan Jumayew, Türkmenistan/Türkmenabat, 1994, Seyis.

KK27:Rajapova Rozihal, Türkmenistan/Türkmenabat, 1961, Hasta ve Yaşlı Bakıc1.

KK28: Farida Açılova, Türkmenistan/Türkmenabat, 1987, Fabrika Çalışanı.

KK29:Dövletcan Bazarov, Türkmenistan/Türkmenabat, 1989, Fabrika Çalışanı.

KK30: Şohrat Arslanov,Türkmenistan/Türkmenabat, 2001, Öğrenci.

KK31: Azad Owezmammadov, Türkmenistan/Aşkabat, 1990, Öğrenci. 